\title{
¿UNA «NOVA ESCOLA DE BARCELONA»? DIÁLOGOS ESTÉTICOS Y NARRATIVOS EN EL CINE REALIZADO POR MUJERES EN CATALUÑA
}

Is There a New "Nova Escola de Barcelona"? Aesthetic and Narrative Dialogues in the Cinema Made by Women in Catalonia

ARNAU Vilaró MONCASía

$\mathrm{ESCAC} / \mathrm{UOC}$

DOI: $10.15366 /$ secuencias2021.53.003

\begin{abstract}
RESUMEN
Desde hace unos años, el cine catalán tiene rostro de mujer. Mar Coll, Liliana Torres, Nely Reguera, Carla Simón, Celia Rico, Meritxell Colell, o Belén Funes. Todas ellas se conocen, comparten procesos, proyectos educativos y sus óperas primas han sido seleccionadas en festivales internacionales, lo que pone en evidencia la existencia de un movimiento que podría dar nombre a una «Nova Escola de Barcelona», esta vez formada por mujeres, y cuyo estudio se revela fundamental para entender la ficción contemporánea en el conjunto del estado español. ¿De dónde surge este espacio de creación protagonizado por mujeres cineastas? ¿Qué procesos comparten y cómo estos influyen en sus obras? ¿Cuáles son sus motivos, sus filiaciones, sus intereses narrativos y estéticos o los referentes que captan su atención? Este artículo intentará arrojar luz a los rasgos que constituyen una nueva ola de jóvenes cineastas que trabajan en Barcelona y cuya fecha de nacimiento encontramos en Tres días con la familia (Tres dies amb la família, 2009).
\end{abstract}

Palabras clave: Nova Escola de Barcelona, Cine español, Cine catalán, Cine contemporáneo, Mujeres directoras, Nuevas directoras, Estética del cine.

\begin{abstract}
In recent years, women directors have been the protagonists of Catalan cinema. Mar Coll, Liliana Torres, Nely Reguera, Carla Simón, Celia Rico, Meritxell Colell, and Belén Funes. All of them know each other, share work procedures, educational projects and their debut films have been selected at international festivals, which highlights the existence of a movement that could be named a «Nova Escola de Barcelona», this time made up of women, and whose study is fundamental to understand contemporary fiction in the whole of the Spanish state. Where did this creative space starring female filmmakers come from? What work procedures do they share and how do they influence their final products? What are their motives, their affiliations, their narrative and aesthetic interests or the references that capture their attention? This paper aims to shed light on the features that constitute a new wave of young filmmakers working in Barcelona and whose date of birth can be located in Tres dies amb la familia (2009).
\end{abstract}

Keywords: Nova Escola de Barcelona, Spanish Cinema, Catalan Cinema, Contemporary Cinema, Women Directors, Film Aesthetic.

[a] ARNaU Vilaró es profesor y guionista. Doctor en Comunicación por la UPF, imparte clases de historia y estética del cine en UAB, ESCAC y UOC. Ha realizado estancias de doctorado y postdoctorado en París III - Sorbonne Nouvelle y en el Instituto de Investigaciones Estéticas de la UNAM. Es autor del libro La caricia del cine (2017) y ha publicado en revistas como Communication \& Society, Historia y comunicación social, Çédille, Cahiers du Grelcef, Área Abierta, Comparative Cinema o Atalante. Ha coescrito Alcarràs (en rodaje) con Carla Simón y formó parte del equipo de dirección de Verano 1993 (2017). Como programador de cine, ha colaborado con instituciones como el Jeu de Paume de París, el Ayuntamiento de Barcelona y la Fundació Obra Social "La Caixa". 


\section{Introducción}

En Desenfocadas, Barbara Zecchi propone una genealogía del cine realizado por mujeres en España, inaugurado por «precursoras» como Elena Jordi y Helena Cortesina, continuado por «pioneras» que trabajaron durante la guerra y el franquismo como Margarita Alexandre y Ana Mariscal, a las que les siguieron las «progenitoras»: Cecilia Bartolomé, Josefina Molina y Pilar Miró a la cabeza. Según Zecchi, estas últimas «sembraron un legado», pero fue en la generación posterior, que la teórica denomina como las «herederas», en la que se produjo una conciencia de grupo entre mujeres cineastas. ${ }^{1}$ Zecchi sitúa dentro de este colectivo a Icíar Bollaín, Isabel Coixet, Chus Gutiérrez, Gracia Querejeta o Patricia Ferreira y, para concebirlas como grupo, fue imprescindible la labor de visibilidad que tuvo la creación de CIMA, la Asociación de Mujeres Cineastas y de Medios Audiovisuales con nacimiento en 2006. Según Zecchi, el relevo de la nueva generación de cineastas culmina en una fecha, 2010, cuando Mar Coll recibe el Goya a la mejor dirección novel con Tres días con la familia (Tres dies amb la família, 2009) «de mano de cuatro directoras (Bollaín, Ferreira, Querejeta y Gutiérrez). Ese suceso supone el relevo de una nueva generación de mujeres cineastas, y simboliza la existencia de una tradición femenina reconocida por la misma Academia». ${ }^{2}$

En el monográfico Cineastas emergentes. Mujeres en el cine del siglo XXI, Annette Scholz se interesa por la continuidad de esta genealogía y, mediante un análisis a la par cuantitativo y cualitativo, constata un aumento lento pero progresivo de la presencia de mujeres en la industria. Junto a la labor de CIMA, Scholz destaca como causas de una mayor visibilidad el trabajo de muestras, festivales y, sobre todo, los movimientos impulsados por el 8-M y surgidos tras el \#MeToo: «desde [el Festival de] San Sebastián a la Semininci, pasando por Alcine o el Jameson Notodofilmfest, se han creado espacios para exhibir películas realizadas por mujeres, se han organizado encuentros temáticos relacionados con la situación de la mujer en el cine y, tras el escándalo de Hollywood que ha salido a la luz bajo el lema \#MeToo, se han mantenido debates sobre el problema del acoso sexual en la industria audiovisual». Las conclusiones de Scholz son claras: las mujeres siguen teniendo poca presencia dentro del sector, algo que ya viene marcado desde su formación, donde no superan el 30\% de matrículas en especialidades de liderazgo como la de dirección, guion y fotografía. ${ }^{3}$ Sin embargo, concluye Scholz después de analizar los reconocimientos obtenidos por mujeres cineastas como Carla Simón, Elena Trapé, Laura Ferrés o Belén Funes, «durante el último año se levanta un aire suave que viene de Cataluña». ${ }^{4}$

Con motivo del ciclo de mujeres celebrado en la SEMINCI de Valladolid en 2017, Carlos F. Heredero reconocía también en Cataluña el principal foco de mujeres directoras del cine español de este siglo y los dividía en tres grupos de cineastas: «un primer impulso de raíces documentales» surgido de formaciones de documental creativo en las universidades UAB (Universidad Autónoma de Barcelona) y UPF (Universidad Pompeu Fabra), ${ }^{5}$ seguido por un «primer brote de ficción narrativa especialmente concernida por diferentes problemáticas femeninas (Roser Aguilar, Mar Coll, Elena Trapé, Leticia Dolera)» y, finalmente, un «segundo impulso de renovación estética y narrativa dentro del ámbito ficcional, que explota con fuerza a partir de 2016 (Nely Reguera, las cuatro directoras de Las Amigas de Ágata, Elena Martín, Carla Simón...)». ${ }^{6}$ Para Eulàlia Iglesias, Las amigas de Ágata (Les amigues de l'Àgata, Laia Alabart, Alba Cros, Laura Rius, MartaVerheyen, 2015) representa la punta de lanza de una generación de nuevas cineastas que, surgidas en muchos casos de las
[1] La misma Cecilia Bartolomé explicaba que, en relación con sus coetáneas, no se concibieron nunca como un colectivo a pesar de que se conocían desde siempre: «no hubo ningún intento de agruparnos». En Diario de noticias, 16 de junio de 2007. Extraído de Barbara Zecchi, Desenfocadas. Cineastas españolas y discursos de género (Barcelona, Icaria, 2014), p. 12.

[2] Barbara Zecchi, Desenfocadas. Cineastas españolas y discursos de género, pp. 10-14, 115.

[3] Annette Scholz establece una reveladora comparación entre la formación universitaria y los trabajadores del sector audiovisual, donde la presencia de mujeres es todavía menor. Entre 2011 y 2015 , se registra un $10,5 \%$ de mujeres en dirección, un $21,15 \%$ en guion y solo un $5,73 \%$ en fotografia. En dirección de producción se registra un $29,15 \%$ de presencia de mujeres que trabajan en el sector a pesar de que las mujeres superan el $50 \%$ de matrículas en esta especialidad. El estudio se realizó en base a los datos facilitados por la Escuela de Cinematografía y del Audiovisual de la Comunidad de Madrid (ECAM) y la Escuela Superior de Cine y Audiovisuales de Cataluña (ESCAC). Véase Annette Scholz, «Las invisibles del cine español» en Scholz y Álvarez (eds.). Cineastas emergentes. Mujeres en el cine del siglo XXI (Madrid, Iberoamericana, 2018), p. 53.

[4] Annette Scholz, «Las invisibles del cine español», pp. 62, 65 .

[5] A partir de películas surgidas en estos másteres como Días de agosto (Dies d'agost, Mar Recha, 2006) o La leyenda del tiempo (Isaki Lacuesta, 2006), Àngel Quintana ya vaticinaba en 2006 que el foco de creatividad del cine español «no tiene su epicentro en Madrid, sino en Barcelona». Véase Àngel Quintana, «Madrid versus Barcelona. O el realismo tímido frente a las hibridaciones de la ficción», en Rodríguez (coord.). Miradas para un nuevo milenio. Fragmentos para una historia futura del cine español (Madrid, Festival de Cine de Alcalá de Henares, 2006), p. 280-284. 
[6] Carlos Heredero, «Directoras españolas en el siglo XXI. Un combate por el equilibrio» en Morán y Yáñez (eds.), Femenino plural. Mujeres cineastas del siglo XXI (Valladolid, SEMINCI, 2017), p. 161, 168-169.

[7] Eulàlia Iglesias, «La década en que dejamos de ser la excepción» (Caimán, 90, 2020), p. 57.

[8] Mar Coll, Carla Simón y Belén Funes obtuvieron el Goya a la mejor dirección novel en 2010 , 2018 y 2019, respectivamente. Las tres películas fueron galardonadas como mejor película - en lengua no catalana en el caso de La hija de un ladrón- en los Premis Gaudí de la Academia del Cine Catalán. Verano 1993 (Estiu 1993, Carla Simón, 2017) fue galardonada como mejor opera prima en la Berlinale en 2018, obtuvo la Biznaga de oro en el festival de Málaga y fue la representante en los Oscar por la Academia del Cine Español. Viaje al cuarto de una madre obtuvo el premio al mejor guion en los Premis Gaudí en 2019 y Julia Ist (Elena Martín, 2017), obtuvo la Biznaga de plata a la mejor película en el festival de Málaga.

[9] Las citas de este apartado provienen de entrevistas realizadas a las siguientes cineastas: Meritxell Colell, Mar Coll, Belén Funes, Nely Reguera y Carla Simón, a quienes el autor agradece su participación en este artículo. escuelas, cuestionan la idea de autoría y los procesos jerárquicos y «con sus óperas primas revisan el imaginario de este tipo de filmes de debut, tan ligado a los procesos de madurez, la pérdida de la inocencia, el primer amor, la mejor amiga y la educación sentimental»?

El siguiente artículo quiere acercarse a esta revisión, a la «renovación estética y narrativa», en palabras de Heredero, de ese tercer grupo de cineastas de ficción que, tras el estreno de otras obras como Con el viento (Meritxell Colell, 2018), Viaje al cuarto de una madre (Celia Rico, 2018) o La hija de un ladrón (Belén Funes, 2019), se consolidan como un movimiento influyente dentro del cine catalán y español. Mar Coll, Liliana Torres, Nely Reguera, Carla Simón, Celia Rico, Meritxell Colell, Belén Funes, Elena Martín o Clara Roquet, todas ellas se conocen, comparten procesos, proyectos educativos y sus óperas primas han sido seleccionadas en festivales internacionales. ${ }^{8}$ A partir de entrevistas realizadas a cinco de ellas, y del análisis de los principales motivos narrativos y estéticos de sus operas primas, pretendemos ver de cerca cuáles son los rasgos que constituyen esta nueva ola de mujeres cineastas cuyo nacimiento, según manifiestan algunas de ellas, tiene una fecha precoz, 2009, con el estreno de Tres días con la familia.

Como vimos, para Zecchi esta película culmina la generación de las «herederas» del cine español. Nuestra hipótesis es que la opera prima de Mar Coll marca el inicio de un espíritu generacional y colectivo del cine realizado por mujeres en Barcelona, dando pie a una serie de temas y decisiones estéticas que toman como centro la exploración de las relaciones familiares y el cine como herramienta de experiencias de vida. Antes de entrar al análisis de sus operas primas, veamos de dónde surge la conciencia de grupo a partir de su trabajo, qué proyectos y procesos creativos comparten estas cineastas.

\section{Hacia una «Nova Escola de Barcelona»: los procesos compartidos ${ }^{9}$}

Dice Meritxell Colell que «vivir los procesos te hace comprender y conectar con lo más profundo y esencial de nuestro oficio». Colell se refiere a una forma de entender el cine que va más allá de un producto final y que pasa por las relaciones que se construyen durante el proceso de elaboración de una película. Para ella, como para el resto de sus compañeras, una parte de este proceso concierne a la colaboración mutua entre cineastas, especialmente durante el guion y el montaje - «un momento clave para volver a ganar la distancia que hemos perdido», dice Coll—, siendo incluso, para algunas, una necesidad: «no concibo hacer cine sin tener el feedback de Meritxell (Colell) en algún momento del proceso», apunta Simón.

Carla Simón conoció a Mar Coll cuando estaba escribiendo Verano 1993 (Estiu 1993, 2017), en un laboratorio de guion de la SGAE: «consistía en varios encuentros para comentar y desarrollar nuestros guiones» $\mathrm{y}$ «compartir el proceso de escritura con Mar y su coguionista Valentina Viso, fue un lujo increíble». Más tarde, conocería a Celia Rico «en un taller de guion en la Berlinale Script Station, de ahí que sobre todo compartamos esta parte del proceso, el guion». Por su parte, Belén Funes compartió el guion de su opera prima, La hija de un ladrón (2019), con la, también guionista, Clara Roquet, «que me dio un buen punto de vista sobre lo que funcionaba y lo que no» y Funes, por su parte, trabajó como script en su opera prima a venir, Libertad (2020). De hecho, Funes empieza a trabajar en cine desde este rol, y, entre las películas en las que colaboró, están algunas de las que formarían parte de la constelación de películas que nos atañe: Todos queremos lo mejor para ella (Tots volem el millor per a ella, Mar 


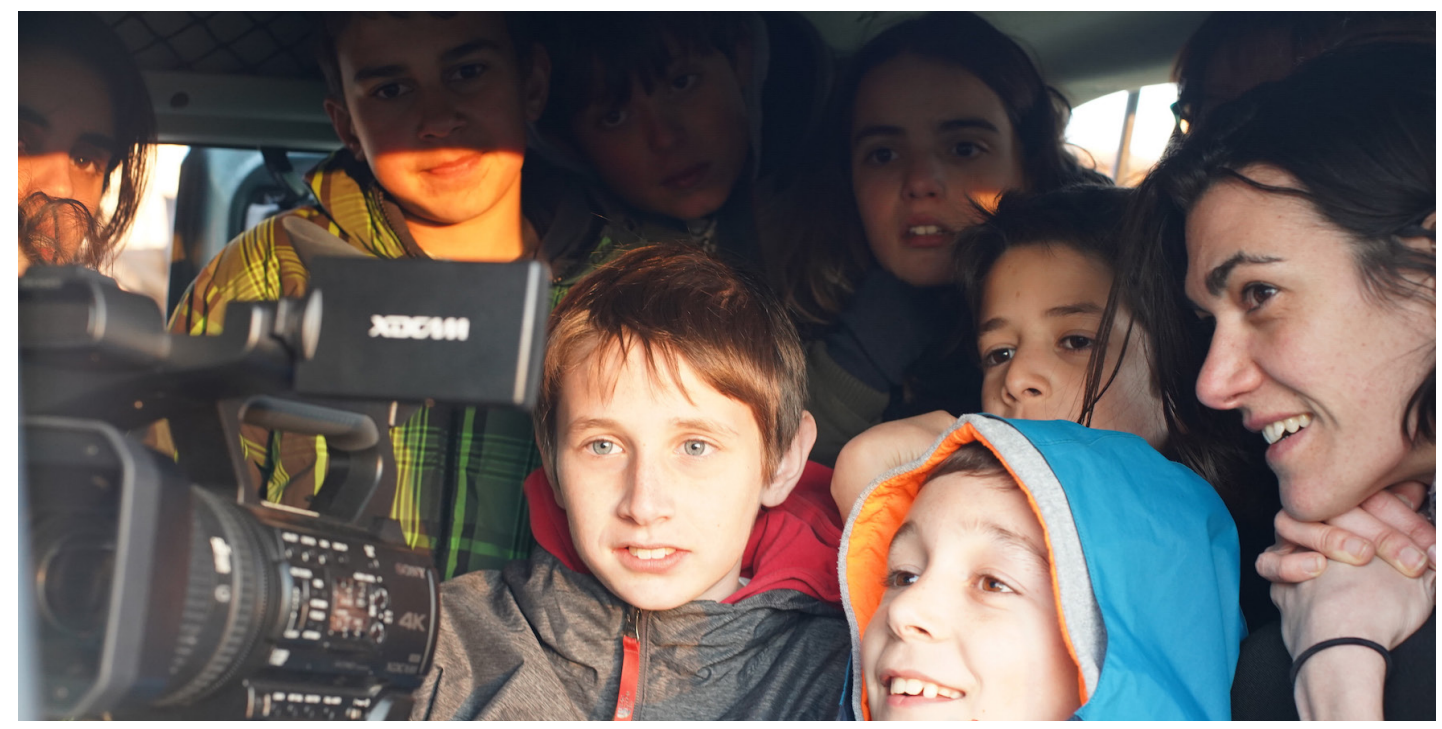

Meritxell Colell junto a alumnos de la Escola Bordils dentro del programa «Cinema en curs».

Coll, 2013), Family Tour (Liliana Torres, 2013) o María y los demás (Nely Reguera, 2016). Reguera, que, como Funes, formaba parte del equipo de dirección de Tres dias con la familia, también trabajó como script de en La hija de un ladrón: «Nely Reguera es mi amiga del alma y durante la película le enseñaba castings, ensayos, hablábamos del guion... Es una forma de trabajar que me parece que aporta cosas buenas a las películas porque los procesos de alguna forma se vuelven más horizontales y yo dejo de sentirme sola contra todo», explica Funes.

Pero estas cineastas no solamente colaboran entre ellas en los procesos de sus obras, sino que también comparten miembros de sus equipos en los que las mujeres son clave. Una de ellas es Valentina Viso, la co-guionista de Mar Coll, que también participó en los feedbacks de guion de Viaje al cuarto de una madre y de Verano 1993 y con quien Simón escribió su último cortometraje, Después también (2019). Otra de las figuras clave es Neus Ollé, responsable de la fotografía de las películas de Coll y de Funes; por su lado, Aina Calleja es la montadora de las películas de Reguera y Coll y, Ana Pfaff, de las películas de Simón y de Colell. Por otro lado, el creciente número de mujeres productoras es otro indicador de peso de confianza a los proyectos dirigidos por mujeres y, según Simón, «esta relación también es clave para entender lo que está pasando en Cataluña». María Zamora, de Avalon, ha trabajado con Simón, con Reguera, con Liliana Torres y Clara Roquet; Carla Sospedra, con Torres, Funes y Simón; Sandra Tapia, de Arcadia, es la productora de Rico, Valérie Delpièrre, de Inicia Films, fue la productora de Verano 1993, también de Los desheredados, así como de la nueva película de Pilar Palomero, Las niñas (2020), la última de las películas revelación del cine español.

Sus relaciones de trabajo y entre equipos evidencian una necesidad de compartir procesos y de entender el cine de forma contraria a lo que Meritxell Colell llama «el cine de los genios», para quien el cine tiene sentido como proceso colectivo: «son la pluralidad de experiencias y sensibilidades tanto del equipo que realiza la película, como de las personas retratadas en ella, como de las espectadoras, lo que hace de una película algo más grande y singular». En este sentido, destaca el rol que, para ella, ha tenido el proyecto pedagógico en el que ha crecido como cineasta, y del que también 
forman parte Celia Rico y Carla Simón, Cinema en Curs, un proyecto colectivo que «reflexiona sobre la transmisión y los procesos» y donde el cine se aborda como una herramienta de aproximación a la realidad. En torno a este proyecto, Simón añade que, en la experiencia de acompañar los proyectos de los alumnos, «partimos de los temas que nos tocan de cerca y eso también es lo que hacemos nosotras cuando nos basamos en experiencias personales».

No es de extrañar, por lo tanto, que tanto Simón como Rico acompañen también en la actualidad los proyectos de las películas que salen de los alumnos de Comunicación Audiovisual de la UPF, cuyo método de trabajo está enfocado a que los alumnos encuentren historias cercanas a su experiencia vital, y de donde salieron proyectos de éxito y con presencia en festivales, como la citada Las amigas de Àgata, seguida por Júlia Ist (Elena Martín, 2017), Yo la busco (Sara Gutiérrez, 2018) o Les dues nits d'ahir (VVAA, 2020). Mar Coll, que estuvo acompañando algunos de estos proyectos, comparte la opinión de Simón cuando piensa en lo que une su trabajo al de sus compañeras: «Creo que todas abordamos el cine con un enorme compromiso y exigencia y como una oportunidad para experimentar, crecer, aprender y comunicar inquietudes personales». También en el ámbito educativo, Coll es la responsable del departamento de dirección de ESCAC (Escuela Superior de Cine y Audiovisuales de Cataluña) y cuenta, entre su equipo, con la colaboración de Funes, Reguera o Rico, lo que resulta fundamental para la creación de nuevos referentes, pues como comenta Belén Funes, «los alumnos se han hecho conscientes de que existe una nueva generación de

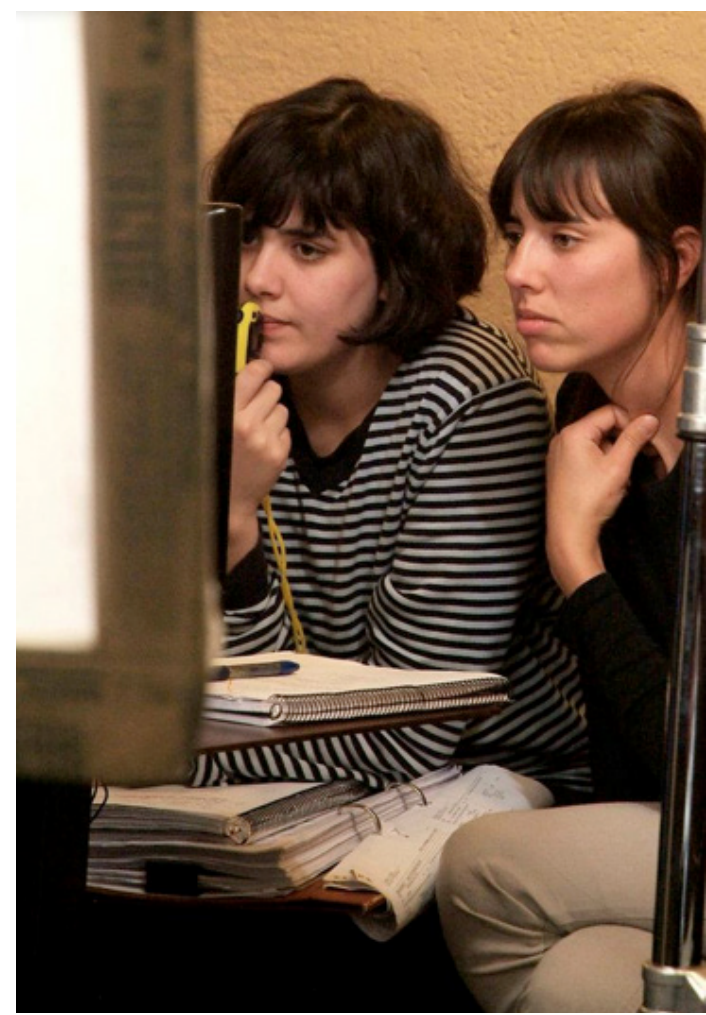

Belén Funes y Liliana Torres durante el rodaje de Family Tour (2013). cineastas mujeres que está haciendo un cine interesante con ciertos ecos en el ámbito internacional y las escuelas nos han dado la oportunidad de ocupar espacios en las aulas formando a los y las cineastas del futuro». Quizás por eso las cineastas mujeres forman parte de sus referentes: Claire Denis es una cineasta que comparten como referente Simón y Colell del mismo modo que Andrea Arnold es una referencia fundamental para Funes y Reguera, pero destacan otros nombres importantes, como Chantal Akerman, Valeska Griesbach, Mia Hansen-Løve o Kelly Reichardt. Funes, Simón y Colell están de acuerdo en que, si algunas de estas cineastas forman parte de sus referencias es porque, según Colell, «en sus películas se hace evidente un cierto desplazamiento de la épica y de la construcción del mito propia de muchos relatos que presiden la historia del cine»y, en palabras de Funes, «construyen personajes femeninos creíbles y complejos, alejados de los estereotipos a los que históricamente estamos acostumbradas».

\section{Diálogos estéticos y narrativos}

En el apartado anterior, quisimos dar voz a las cineastas para conocer, desde su experiencia y a partir de sus propias palabras, la constelación de relaciones que se genera tanto en los procesos creativos como dentro de acompañamientos como docentes. Esto explicaría el 
surgimiento de una posible «Nova Escola de Barcelona». Pero ¿de qué modo estos procesos se traducen en diálogos estéticos y en intereses narrativos comunes? En los próximos apartados intentaremos responder a esta pregunta a partir de tres ejes. En primer lugar, desde el retrato de las relaciones familiares como tema que preludia Tres días con la familia y al que recurren todas las películas de esta generación de cineastas. En segundo lugar, nos centraremos en la autoficción, o en un interés por lo que Philippe Lejeune definió como el «pacto autobiográfico» entre el autor y el receptor de la obra; ${ }^{10}$ y es que, según Scholz, nos encontramos delante de «unas directoras que en su mayoría abordan en sus películas experiencias vividas en primera persona». ${ }^{11} \mathrm{El}$ último apartado lo dedicaremos al interés de algunas de estas cineastas por mostrar el crecimiento de la protagonista y, en concreto, a la revisión del imaginario del comingof-age a la que se refería Eulàlia Iglesias en torno a los films de debut.

\section{1 «La familia es algo que no vas a poder cambiar» ${ }^{12}$}

Philipp Engel consideraba a Mar Coll como el «hada madrina» de este grupo de cineastas. ${ }^{13}$ Nely Reguera explica que «trabajar en el rodaje de Tres dies amb la família fue muy inspirador, esa película representaba el tipo de cine que me interesaba y quería hacer». Para Carla Simón, «Tres dies amb la família fue un punto de inflexión en mi vida, porque me demostró que lo que deseaba hacer era posible». ¿Qué fue lo que reveló esta película a las directoras que le siguieron?

En Tres días con la familia, Léa (Nausicaa Bonnín) viaja a Girona para asistir al funeral de su abuelo. Entre el tanatorio, los desayunos con su padre y una comida en la finca de sus difuntos abuelos, en sus tres días con la familia, Léa es incapaz de poner palabras a la incomodidad que le invade y que la convierte en una persona cada día más irascible. La protagonista sufre todavía el duelo de la ruptura de sus padres $\mathrm{y}$, a este duelo, se le une el miedo de perder la relación con su novio de Toulouse, un problema sentimental que Léa es incapaz de comunicar a una familia acostumbrada a fingir y a guardar secretos. Léa romperá el silencio finalmente con un llanto de liberación y de culpa al mismo tiempo, poco después de que su madre la abandone en el columpio de la finca, en una imagen que expresa la pérdida de la infancia, mientras la madre le recuerda a su hija que nunca nadie tomará una decisión por ella: «si no te gusta tu vida, cámbiala». Coll pone el foco en «los personajes femeninos, captados en momentos de crisis, de cambio, de descubrimiento» y, más concretamente, «se trata de una crisis y una transformación no elegidas, sino sufridas». ${ }^{14}$ He aquí la mudanza de la amiga en La última polaroid (2004), la separación en Tres días con la familia o el accidente que sufre Geni (Nora Navas) en Todos quieren lo mejor para ella. Retratando tres momentos vitales (infancia, juventud y edad adulta), en cada película Mar Coll explica una afectación provocada por un cambio ajeno y su incapacidad por resolverlo, o cómo la imposibilidad de avanzar por uno mismo viene dada por la dificultad de cuestionar o romper los lazos familiares.

Según Nely Reguera, la familia interesa porque «es algo que no vas a poder cambiar» y puede que así lo piense también la protagonista de su ópera prima, María (y los demás). A sus 35 años, María (Barbara Lennie), soltera y con una novela que lleva años escribiendo y que no consigue publicar, es la única mujer de la familia y asumió el rol de su madre después de que falleciera hace 15 años. Pero su vida empieza a tambalear cuando su padre, a quien dedica todo su cuidado, anuncia que se casa con la enfermera del hospital. Esto ocurre en una escena de celebración en familia y
[10] Philippe Lejeune, El pacto autobiográfico y otros estudios (Madrid, Megazul-Endymion, 1994), p. 133.

[11] Annette Scholz, «Las invisibles del cine español», p. 67.

[12] Palabras de Nely Reguera a Carlos Losilla «Una cuestión de tono. Entrevista con Nely Reguera» (Caimán, 55, 2016), p. 32.

[13] Philip Engel, «La generación Àgata» (Fotogramas, 2085, julio 2017), p. 96-101.

[14] Giulia Colaizzi, «Mar Coll: horizontes de crisis», en Fran A. Zurian (ed.). Miradas de mujer. Cineastas españolas para el siglo XXI (Madrid, Fundamentos), p. 120. 


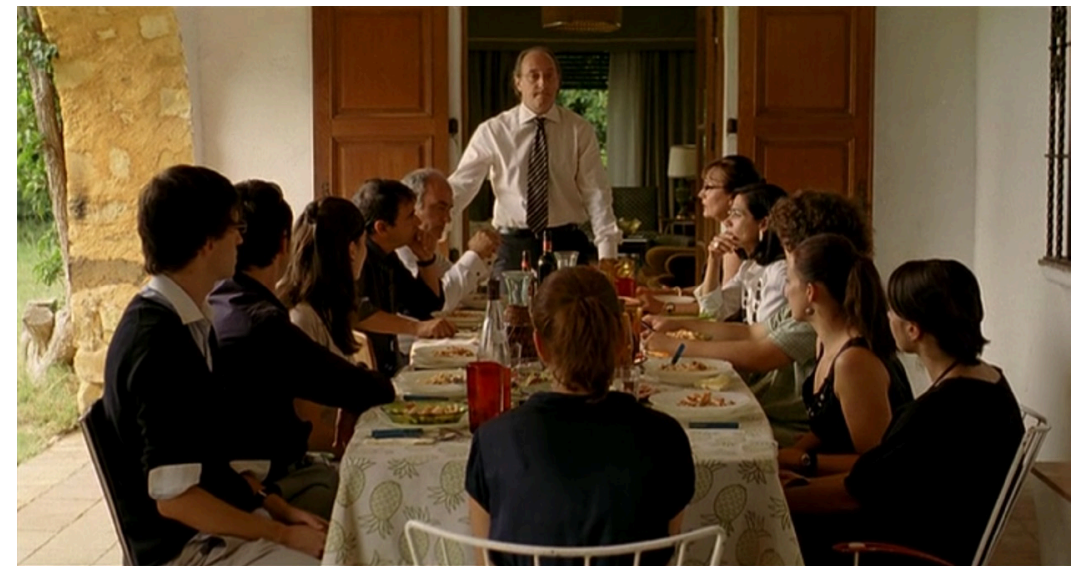

La presencia de la hija en la familia. Izquierda, Tres días con la família; abajo, María (y los demás) (Nely Reguera, 2016).

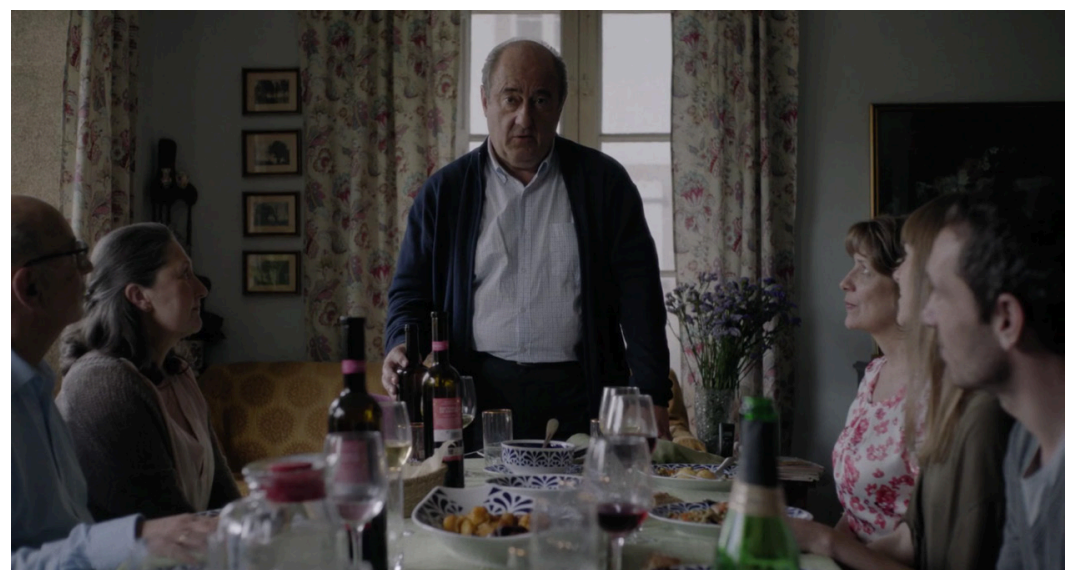

Reguera sitúa al espectador en un cara a cara entre el padre y la hija parecido al de Tres días con la familia entre el tío rico de la familia (Ramon Fontserè) y Léa. La vida de María se desmorona a partir de este momento, no tanto porque esa desconocida mujer sea una amenaza a la figura de su difunta madre, sino porque es ella misma quien se ve sustituida. María bebe del retrato de mujer dedicada a la vida de los otros y, como la protagonista de Jeanne Dielman (Chantal Akerman, 1975), encuentra su zona de confort en la cocina y el cuidado de la familia hasta que la noticia del matrimonio de su padre le hace ver que nunca tuvo la fuerza para cambiar lo que no le gustaba de su vida. En palabras de Reguera, «ella se ha acomodado en esa situación familiar, y la familia también ha contribuido a que lo haga. Para ella, todo es una excusa para no afrontar su vida». ${ }^{15}$ María tiene que replantearse su día a día al verse desplazada de su propia casa, ese lugar que, como decía Marguerite Duras, solo las mujeres conocen: «yo en esta casa, con este jardín, mantengo relaciones que los hombres no tendrían nunca con un hábitat, un espacio». ${ }^{16}$ María tiene esta relación con la casa de la que

[15] Carlos Losilla, «Una cuestión de tono. Entrevista con Nely Reguera», p. 33.

[16] Michèle Porte, Los espacios de Marguerite Duras (Madrid, Ediciones del Oriente y del Mediterráneo, 2011), p. 13. ahora se ve forzada a irse, y eso empieza con la preparación de la boda de su padre, con la discusión en torno a una planta del jardín que lleva allí muchos años pero que a su padre no le importa cortar, y termina cuando sus cosas desaparecen de su armario en una repentina mudanza.

La opera prima de Celia Rico, Viaje al cuarto de una madre, explica la relación entre una madre, Estrella (Lola Dueñas), y su hija Leonor (Anna Castillo) a través de 
su apartamento. La casa funciona aquí como matriz y, como señala la misma Rico, como el cuerpo que une madre e hija:

Esta idea de romper el vínculo, de romper el cordón umbilical y salir de casa, está muy relacionada con la maternidad. Con cómo de un cuerpo puede nacer otra persona, cómo se puede ser dos y, a la vez, ser uno. Todo el proceso de maternidad está atravesado por la idea de unión y separación. Este juego físico me interesaba mucho. $^{17}$

El segundo plano de la película expresa el corte del cordón umbilical, cuando el personaje de Lola Dueñas, costurera como la madre de la cineasta, termina de retocarle un vestido y corta con unas tijeras la parte que le sobra. «Te han crecido», le dice Estrella; «no, es la regla», responde Leonor. Si el diálogo evidencia el crecimiento de Leonor, su mirada, perdida y fuera de campo, indica que ya ocupa un lugar fuera de su casa. La película explica el proceso de emancipación de Leonor de su madre, que hace pocos años que se quedó viuda. Ese proceso empieza cuando el personaje que interpreta Anna Castillo decide irse a Londres y trabajar como au pair con la excusa de mejorar su inglés.

Sin embargo, a Rico no le interesa seguir el personaje de Leonor en su viaje, sino permanecer en el piso, espacio de la relación entre madre e hija y lugar de resistencia entre la unión y la separación de la maternidad a la que se refiere la cineasta. A medida que la película avanza, la casa se erige como el punto de vista - el verdadero protagonista de la historia - y, como en la ya citada Jeanne Dielman, la cámara no acompaña a los personajes, sino que se mantiene fija. Esta decisión formal enfatiza la intención de la cineasta de privilegiar el espacio por encima de todo: la cocina, el salón, el baño, el cuarto de coser y, sobre todo, las dos habitaciones, situadas frente a frente y con la puerta siempre abierta, para que en un cuarto siempre esté el otro — de nuevo, una imagen que resume la relación entre madre e hija-. Rico sintetiza también el cuerpo que une madre e hija a través de «un objeto que es muy común en mi tierra, en Andalucía, y que es la mesa camilla». ${ }^{18}$ Esa mesa camilla expresa el viaje de unión, separación y asunción de su nueva relación: en el primer plano de la película, ambas se protegen con ella para ver juntas la serie; cuando Leonor abandona el hogar, la estufa quema la manta con la que se cubrían madre e hija y, cuando Leonor regresa de Londres, instalan una nueva mesa entre las dos, ahora más pequeña, porque Estrella sabe que, a partir de ahora, va a quedarse sola. La mesa camilla, junto a la cafetera que no pueden abrir sin la ayuda de la otra, habla de la importancia de los objetos en esta película, objetos que también definen la figura de un difunto padre: a través de sus camisas y sus zapatos, de una bici estática o del acordeón escondido en el armario que Leonor hará sonar la noche de su regreso a casa.

La ausencia del padre está presente también en Con el viento y, para abordar el duelo, Meritxell Colell busca también esta dimensión física del espacio compartido, en su caso, entre tres generaciones de mujeres: la abuela Pilar (Concha Canal), sus dos hijas Mónica (Mónica García) y Elena (Ana Fernández), y su nieta Berta (Elena Martín). Pero aquí solo Pilar conoce el día a día de ese lugar. Mientras que Elena, durante todo este tiempo, ha visitado a sus padres yendo y viniendo de Barcelona, Mónica, la protagonista, regresa desde Buenos Aires después de muchos años. Junto a la casa, Mónica se alejó de su tierra y de su pasado, de su madre y, por supuesto, de un padre a quien no tuvo tiempo de decir adiós. Con el viento plantea un viaje de
[17] Palabras de Celia Rico a Fernando Bernal, «'Me gusta quedarme con lo esencial'. Entrevista a Celia Rico» (Caimán, 74, 2018), p. 44 .

[18] Palabras de Celia Rico a Fernando Bernal, «'Me gusta quedarme con lo esencial'. Entrevista a Celia Rico», p. 44. 

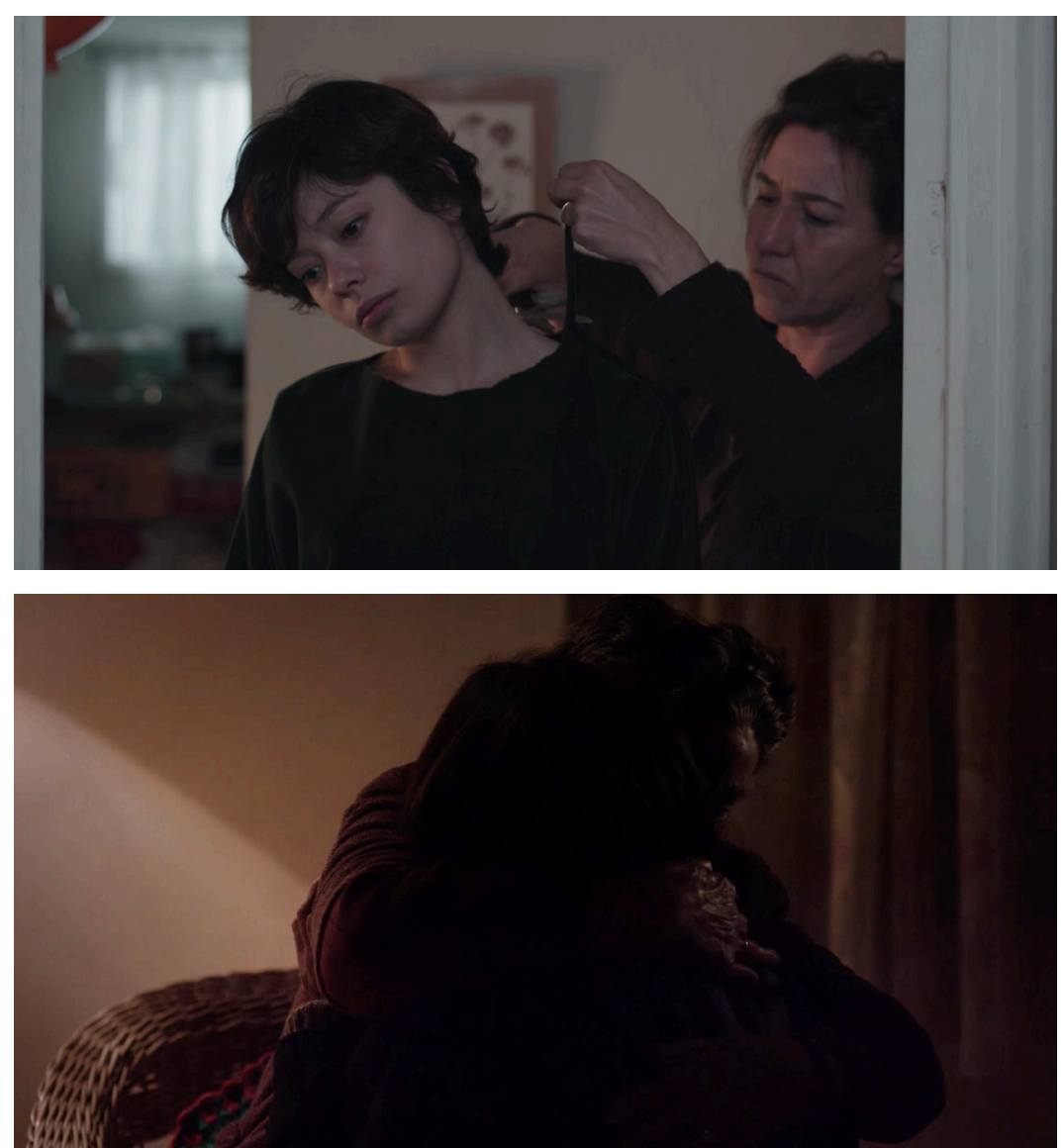

Relaciones entre madres e hijas a través del cuerpo. Arriba, Viaje al cuarto de una madre (Celia Rico, 2018); abajo, Con el viento (Meritxell Colell, 2019).

reconexión desde el cuerpo de Mónica, una bailarina que, estando en el lugar en el que creció, parece haber perdido su capacidad motriz. Todo ocurre como si, para poder bailar, antes tuviera que volver a aprender a ocupar el espacio y, después, encontrar un sentido a su movimiento. He aquí el último plano secuencia de la película, con el que Colell parece reunir el espíritu del cine de Roberto Rossellini en Stromboli (1950) y los movimientos de cámara de Claire Denis cuando esta filma a la coreógrafa Mathilde Monnier en Vers Mathilde (2005). Rodado a la salida del sol, este plano final revela el aprendizaje de la protagonista: Mónica baila con y contra un viento que, según Colell, «marca los rostros de la gente que vive ahí» a la vez que remite a la fuerza de un pasado que nunca dejó de soplar y que, hasta este momento, Mónica no puede afrontar.

La relación de Mónica con su madre se expresa también, y fundamentalmente, mediante gestos. Desde el primer abrazo entre ambas, un abrazo largo, fuerte y silencioso y cuya intensidad vuelve a aparecer cuando se cogen de la mano durante la visita a la agencia inmobiliaria. Son gestos que expresan el dolor, el miedo y el amor, también la satisfacción, como cuando Pilar mira a su hija colocando de forma ordenada los troncos que necesitarán para encender la estufa durante el invierno. Gestos de una comunicación con la que ambas comparten el silencio que les invade: el que 
acompaña al duelo de Pilar y el de la culpa de no haber estado al lado de sus padres en el caso de Mónica. El perdón de la protagonista a su hermana —ella sí se expresa con palabras - llega hacia el final de la película, pero el clímax pertenece a otro momento, cuando la sobrina Berta le dice a Mónica: «el abuelo me contó que no te había visto bailar y que se arrepentía muchísimo». Mónica no podrá disimular una lágrima a lo largo de un largo plano compartido entre ambas. A partir de este momento, tía y sobrina compartirán siempre encuadre, lo que expresa otro tipo de relación de proximidad, conectada con el secreto. Después de la confesión de Berta, Mónica no deja que con su madre ocurra lo mismo que con su padre y por eso, de noche, como Leonor en el film de Celia Rico, viaja a su cuarto para enseñarle un vídeo de su último trabajo.

\subsection{La ficción como aproximación a la realidad}

El rodaje de Con el viento tuvo lugar en un pequeño pueblo del norte de Burgos de tan solo seis habitantes, localidad en el que residían los abuelos maternos de la cineasta. Colell estuvo varios años documentándolo, pero fue a través de la ficción que pudo aproximarse de otro modo a la realidad de ese lugar: después de doce semanas de rodaje, con un equipo muy reducido y rodando en cronología para que todo el mundo fuera partícipe del proceso de construcción. El fuera de campo del rodaje también era importante para Rico, que quiso rodar en su pueblo natal sevillano en Viaje al cuarto de una madre, no para mostrar sus exteriores, sino para que, durante el rodaje, el equipo captara la atmósfera del lugar.

Como en gran parte de las óperas primas, la biografía es uno de los rasgos fundamentales de estas cineastas. Pero, para ellas, su vida no funciona como inspiración solamente, sino como el lugar de las emociones vividas: de aquí ese interés por volver a los espacios, de partir de los lugares y los rostros que formaron parte de sus vidas. En ocasiones, hay un compromiso - y casi una responsabilidad ética - con la biografía. Uno de los gestos más radicales lo encontramos en Los desheredados (Laura Ferrés, 2017) cuando, en plena crisis económica, el padre de la cineasta tuvo que cerrar su empresa de autobuses, un negocio familiar con cuarenta años de historia. Ferrés tenía solo dos meses para pensar y rodar una película, el tiempo que le quedaba a su padre antes de abandonar la empresa. Para Ferrés, que también incluye a su abuela en el elenco, con la película podría crear un recuerdo familiar, pero se trataba también de un gesto de responsabilidad, de devolver a sus padres la oportunidad que le dieron de estudiar cine. Esta responsabilidad estaba ya en la raíz de su cortometraje de graduación, A perro flaco (2014), que narra la historia de una joven a quien las cosas no le van bien, pero cuyo objetivo principal es el de no defraudar a su madre.

Family Tour (Liliana Torres, 2016) se construye también desde lo biográfico, pero su intención no reside tanto en generar una ficción a partir de lo real, sino en explorar el intersticio entre la realidad y la ficción. La película cuenta la historia de Lili (Núria Gago), una joven post-universitaria que nació en un pueblo de Cataluña y lleva un tiempo viviendo en México, donde ha empezado su carrera como cineasta. La película narra la visita de Lili a su familia a través de un tour por las casas de sus familiares, siempre a remolque de su madre. La situación de la protagonista es la misma que la de la directora, también su casa en Sant Bartomeu del Grau, pero también lo es la familia que aparece en pantalla, siendo el personaje que interpreta Gago el único propiamente «ficticio». Ese dispositivo le permite a Torres adentrarse en el espíritu de lo que quiere contar: mostrar su situación como una imagen asincrónica, que ha 
perdido su relación original. Si otro cuerpo ocupa su lugar es porque la imagen de la cineasta no corresponde con la que su familia cree que es. Lili sigue siendo tratada como la niña que fue cuando vivía allí, faltada de autonomía, nadie conoce realmente su vida y sufre el hecho de no cumplir con las expectativas de todos ellos. Cansada de no poder tomar decisiones por su cuenta, Lili visita a una amiga compositora, Joana (Joana Serrat), que le encarga realizar los visuales para el estreno de su nueva canción. Para ello, Lili no se inspira en la canción, sino en el sentimiento de desarraigo que le produce su regreso a casa. En los visuales, se filma a ella misma desnudándose, y después se viste con ropa de niña pequeña para mostrar una infancia de la que Lili no termina de escapar y por eso decide montar los visuales en loop. Lili pedirá a su padre que le acompañe a la proyección, pero este solo es capaz de ver un gesto ofensivo al mostrarle en público imágenes en las que aparece en ropa interior sin entender que lo que ella quería expresarle era la pérdida de la infancia. El interés por la autobiografía de Liliana Torres continuará en su próxima película y de estreno inminente, ¿Qué hicimos mal? (2021), donde la cineasta se pone esta vez ella misma delante de cámara para convertir en ficción encuentros con sus ex-parejas reales.

Para realizar Verano 1993, Carla Simón difícilmente podía renunciar a las imágenes de su recuerdo, a todo lo que, a través de sus abuelos, de sus tías y de sus padres
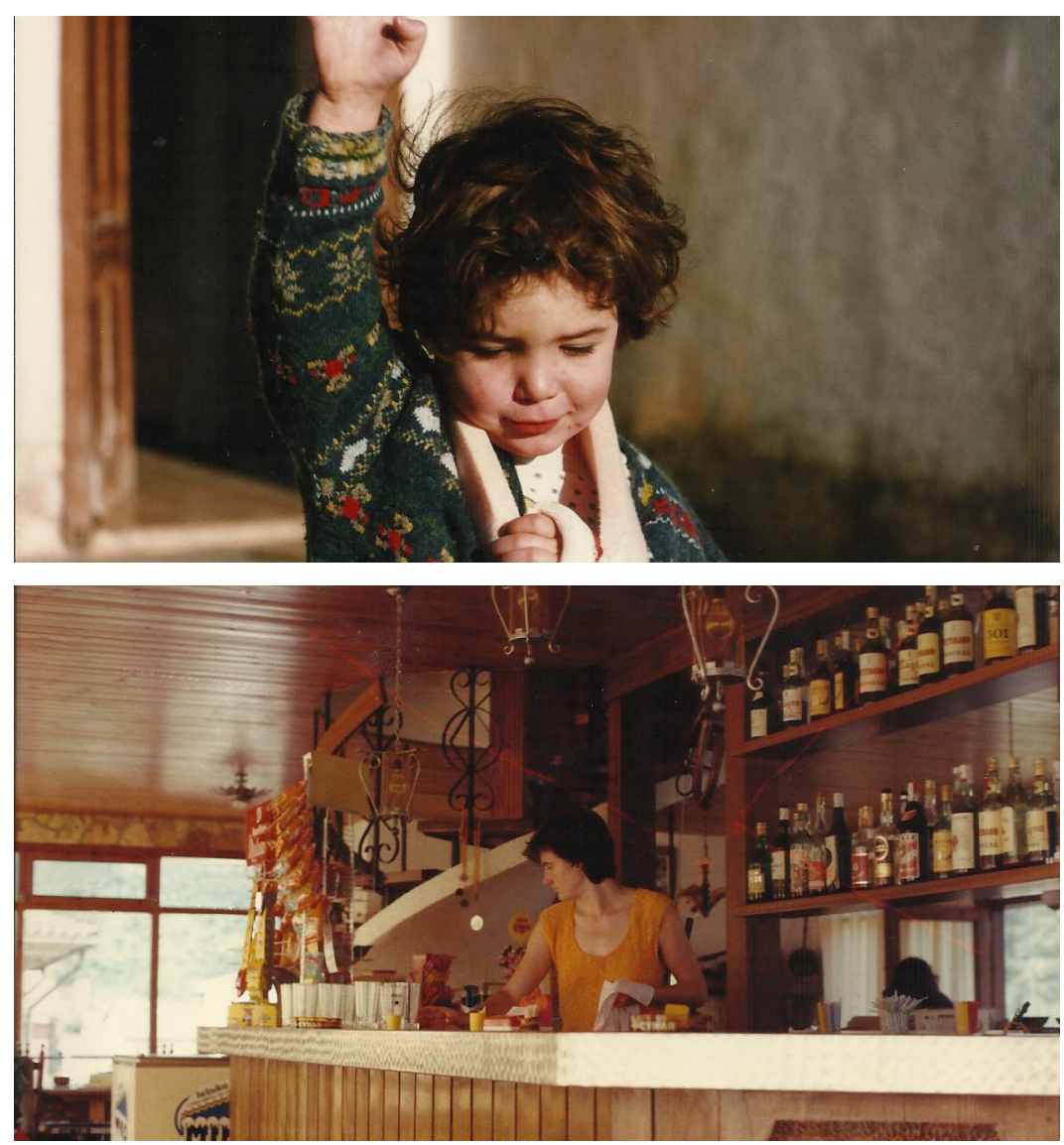

Fotografías del álbum familiar de Carla Simón que la cineasta tomó como inspiración durante el proceso creativo de Verano 1993 (Carla Simón, 2017). 
adoptivos, llegó a conocer de su madre biológica, Neus Pipó, lo que le permitió crear una memoria de su infancia y de su madre. En su ópera prima, Simón quiere poner imágenes al momento en el que, de la noche a la mañana, abandonó un lugar y se encontró perteneciendo a otro. El film arranca con la pérdida de la madre y la mudanza de una casa en Barcelona y, a partir de aquí, Frida (Laia Artigas), álter ego de la cineasta, se enfrenta a un doble viaje: entender y superar el duelo y adaptarse a una nueva familia. Una de las grandes ambiciones del proyecto se encontraba no tanto en crear la réplica de las mismas imágenes del recuerdo, sino más bien aproximarse al sentimiento de su experiencia. He aquí uno de los momentos que para la cineasta eran cruciales de retratar: cuando, hacia la mitad del metraje, recibe la visita de los abuelos y Frida quiere marcharse con ellos, pero no lo consigue. Estas imágenes del recuerdo de la cineasta conviven con los objetos y los espacios reales: una bici, el brazo escayolado de la hermana, el tapiz que cuelga en la pared de la habitación de los padres o las piscinas del pueblo vecino en las que estos trabajaron, el Padrenuestro que la abuela le obligaba a recitar, su tía con nanismo o el llanto en la habitación con el que Carla daría por cerrado el viaje de Frida. Como en Family Tour y Los desheredados, aquí también existe una voluntad de inscribir la memoria familiar: la hermana de Carla -Anna en la ficción - es actriz e interpreta del rol de Tía Ángela (Berta Pipó), y su hermano, Ernest Pipó, que todavía estaba por nacer en el tiempo en el que se sitúa la ficción, se encargó de la banda sonora y una de las canciones que interpretó fue una versión de una composición hecha por el padre adoptivo de Carla, Salvador Pipó.

Para explicar ese momento de su infancia, Simón requeriría de la familia con la que creció, quizás para mostrar lo que permanece vivo de lo que formó parte de su pasado, aunque la preocupación mayor de la cineasta sería la incapacidad de mostrar lo que ya no estaba: su madre biológica. ¿Cómo representar la ausencia de la madre? Esta pregunta estuvo presente a lo largo del proceso de escritura y concepción visual de la película. De aquí surgió un trabajo que la cineasta tuvo la necesidad de rodar durante la preproducción de su largometraje. Se trata de Llacunes (2017), un pequeño film que dialoga con el fuera de campo de Verano 1993, donde la cineasta lee las cartas de su difunta madre mientras visita los lugares en los que fueron escritas, un material, el de esas cartas, que Simón recuperará para una película en fase de escritura y que lleva por título Romería.

En Verano 1993, la madre está presente también desde los objetos, algunos de los cuales ya se hacen visibles en la primera secuencia de la película, cuando, en plena mudanza, Frida observa la habitación medio vacía de su madre y se sienta reflexiva en su sillón, sin entender demasiado aún el movimiento que la lleva a observar el espacio. Son los mismos objetos que Frida entregará a la virgen que encuentra escondida cerca de la casa de su vecino y a través de la cual, como en las plegarias de la protagonista de Ponette (Jacques Doillon, 1996), intentará comunicarse con su madre, en su caso, ofreciéndole estos objetos: un paquete de tabaco, una camisa de topos, un abanico. Pero Neus está presente también en las imitaciones que Frida hace de ella jugando con su nueva hermana Anna: en el gesto de fumar con sus botas puestas, las gafas de sol y el maquillaje. Cuando juega a imitarla, Frida utiliza las palabras que Carla encontró en las cartas escritas por su madre: «estic cantitat de cansada», «em fa molt mal el cos», «enrotlla’t». Estas frases, que la actriz tenía que memorizarse, tenían que dar paso a la improvisación, lo que permitió que, durante el rodaje, cada toma fuera distinta dado que Anna tenía siempre un nuevo juego pensado después de que Frida le dijera «digue'm, filla, a què vols jugar». La escena es significativa al menos por 
dos motivos: porque encuentra una representación del recuerdo a través del juego y porque sintetiza el estilo de una dirección de actores que funciona como credo para la cineasta, a medio camino entre un guion en el que todo está escrito y generar el espacio adecuado para que los actores interpreten desde sí mismos. En este lugar, nada lejano de lo que planteaba John Cassavetes en su cine, también se encuentra para Colell el mejor método de trabajo, cuando explica que «todo está escrito y, al mismo tiempo, la película final no tiene nada que ver con lo que era el guion. [...] Cuando aprendes a dejar que los personajes sean como son las actrices, a darles ese espacio de libertad y de confianza, eso es un gran aprendizaje...». ${ }^{19}$

\subsection{La fortaleza de lo vulnerable}

Las heroínas de estas películas parten de un fuera de lugar y permanecen en él porque, en cierto sentido, controlarlo no depende de ellas. Esto las sitúa en un estado de vulnerabilidad y las cineastas se sirven de ese estado para encontrar su fortaleza - de la psicología del personaje, pero también de la narración y su dispositivo formal-en las derivas del viaje emocional del personaje. De nuevo, las palabras de Marguerite Duras pueden sernos esclarecedoras. La escritora y cineasta decía que solo le gustaba la gente vulnerable porque «son los únicos realmente vivos», y añadía que «la mujer tiene esta gracia, la de estar en una pérdida constante... estar perdido es magnífico. Y eso viene de la infancia. Todos los niños están perdidos...». ${ }^{20}$ Léa en Tres días con la familia, Geni en Todos queremos lo mejor para ella, María en María (y los demás), Lili en Family Tour, Mónica en Con el viento, Frida en Verano 1993, Leonor en Viaje al cuarto de una madre o Sara en La hija de un ladrón. Todas ellas aprovechan el sentimiento de pérdida, de vulnerabilidad del personaje, para construir un arco sólido.

En esa fascinación por la vulnerabilidad, Duras sitúa en el mismo lugar a la mujer y a la infancia, y esto explica el interés por los films de crecimiento, el coming-of-age, donde el retrato de Frida en Estiu 1993 tiene una continuidad en personajes posteriores como el de Marta en El viaje de Marta (Staff Only) (El viatge de la Marta [Staff Only], Neus Ballús, 2019), Celia en Las niñas (2020) o Nora en Libertad, la ópera prima de Clara Roquet, una película que a su vez guarda continuidad con el anterior cortometraje de la cineasta, El adiós (2015). También en esta genealogía deberíamos ubicar los proyectos que salen del Grado de Comunicación Audiovisual de la UPF, desde su obra impulsora Las amigas de Àgata a Júlia Ist, pero también piezas posteriores como Ojos negros (VVAA, 2019) o Les Perseides (VVAA, 2019).

Con la excepción de Viaje al cuarto de una madre, en todos estos films se produce un seguimiento de personaje. Sin embargo, sus directoras tienen claro que el punto de vista no es solo una cuestión de relación entre la cámara y el personaje, sino de entender la película como un espacio para explorar la psicología de su personaje. En este sentido, la película se entiende como un viaje que parte del cuerpo de la actriz y termina ofreciendo una salida que, en la mayoría de los casos, tiene forma de lágrima.

En Verano 1993, ese viaje viene marcado por la primera frase de la película. Frida

[19] Palabras de Meritxell Colell a Carlos Heredero, «Habitar las películas. Entrevista con Meritxell Colell» (Caimán, 76, 2018), p. 69.

[20] Palabras de Marguerite Duras a Christiane Blot-Labarrère, Marguerite Duras (París, Seuil, 1992), p. 15-16. juega al escondite inglés, su cuerpo, paralizado, expresa su incapacidad de reacción y, en este estado de inmovilidad, su primo le pregunta: «I tu per què no estàs plorant?». La película se plantea como una respuesta a esta pregunta y reserva la última escena del film para culminar la acción, a través de un plano secuencia en el que Frida pasa de saltar de emoción en la cama con su hermana hasta romper en lágrimas para terminar dedicando una mirada de reconocimiento a cada miembro de su nueva familia. En $L a$ 
hija de un ladrón, las lágrimas de Sara caen en la última escena, delante del juicio para tener la custodia de su hermano Martín. El momento es incómodo, la protagonista se encuentra completamente indefensa y el plano, casi frontal y suspendido en el tiempo, así lo expresa. El tribunal espera que Sara diga algo, que responda a una pregunta que la muchacha nunca se había hecho: ¿qué puede ofrecerle ella a su hermano?, ¿por qué ha de tener ella la custodia? Sara se encoge de hombros, duda, seguramente por un momento imagina su vida cuidando de un bebé y de un hermano y sin ninguna ayuda más, y, en este momento, rompe a llorar. Este plano final, que pone a Sara al descubierto, desarmada delante de unos desconocidos — ni su abogado la conoce en persona-, contrasta con el primer plano de la película, en el que la protagonista aparece protegida con un pañuelo y de espaldas, escondida en su propia figura.

La semilla de La hija de un ladrón ya estaba en el primer cortometraje de Funes, Sara a la fuga (2015), la historia de una adolescente que vive en un centro de menores porque su padre está en la cárcel. A Funes le interesa la soledad y el crecimiento de ese personaje después de haber estado lejos de su padre. En La hija de un ladrón, la nueva Sara quiere construir una familia, quizás quiere ser una «persona normal». Es lo que responde, siempre dudando, cuando le preguntan «¿cómo eres?». Pero la inquietud por volver a ver a su padre sigue estando en la mirada de la Sara que interpreta Greta Fernández: sigue ilusionándose cuando su padre le dice que le llamará o cuando le promete que se irán a vivir juntos. Esa nueva Sara sabe, como dice hacia el final de la película, que «lleva a su padre en el rostro», y lo dice para que el espectador no olvide que el rol del padre lo encarna el mismo padre de Greta, Eduard Fernández. Estos dos rostros ya formaban parte de una misma familia en Tres días con la familia y la decisión de que sean padre e hija en La hija de un ladrón no es baladí en un film que trata sobre la imposibilidad de escapar de los lazos biológicos.

\section{A modo de conclusión}

A partir del diario que Luc Dardenne publicó después de El niño (L'enfant, 2005), Núria Aidelman escribe que, en el cine, filmar la nuca tiene que ver con «el enigma y la resistencia de los personajes», y añade: «tras sus espaldas, los cineastas descubren el mundo con ellos o evidencian su opacidad». ${ }^{21}$ La hija de un ladrón no solo toma la herencia del cine social de los Dardenne, sino también su estilo de cámara para seguir un rostro desde su opacidad y conocer, desde este mismo lugar, el mundo que le rodea. ${ }^{22}$ Esta forma de ver descubriendo con el personaje es algo que el film de Funes comparte con el resto de películas que estudiamos a lo largo de estas páginas. Expresión de un colapso físico (Con el viento), de una incomodidad (Tres días con la familia, Family Tour) o de una incomprensión (Verano 1993), la opacidad de las protagonistas de estas películas parte de una incapacidad de expresión que a menudo se traduce en una falta de palabras. Su forma de comunicarse pasa por otro lugar. Pensamos en los gestos que en Con el viento crean la relación entre Mónica y su madre Pilar, también en las peleas que, como una forma de jugar, se dan entre Sara y Dani en La hija de un ladrón, en la mano que Léa aparta de su cuerpo cada vez que alguien intenta mostrarle afecto en Tres días con la familia o en el robo de Frida de las flores del vecino como una forma de aproximarse a su nueva madre en Verano 1993. A los gestos de relación, debemos añadir un interés por los gestos que expresan la soledad del personaje y que permiten aproximar al espectador a su psicología y, por lo tanto, a su opacidad. En este sentido, no parecen casuales los
[21] Núria Aidelman, «La nuca», en Jordi Balló y Alain Bergala (coords.), Motivos visuales del cine (Barcelona, Galaxia Gutenberg, 2016), p. 177.

[22] Véase Àngel Quintana, «Cuando se pierde la inocencia. La hija de un ladrón» (Caimán, $88,2019)$, pp. 22-23. 
recurrentes momentos en la habitación, desde donde Léa llora o se esconde de sus padres en Tres días con la familia, Frida recuerda el Padrenuestro que le enseñó la abuela en Verano 1993, o Leonor observa con duda el cuarto de su madre Estrella en Viaje al cuarto de una madre.

El gesto, la mirada, el silencio o la escucha son las herramientas con las que estos personajes plantean una relación con el mundo y afrontan la pérdida o la separación, temas a los que todas estas cineastas recurren. Y aquí, los objetos tienen un rol clave para revelar las ausencias sin la necesidad de las palabras: en Verano 1993 o en Viaje al cuarto de una madre, el rostro de la madre y el padre, respectivamente, se construye mediante los objetos. Pero los objetos también hablan de la relación de los personajes con los lugares: hacia el final de Con el viento, Berta quiere llevarse a Barcelona las albarcas que su abuela ya no quiere porque en la ciudad ya no va a utilizarlas; en Viaje al cuarto de una madre, la relación con la mesa camilla encarna la evolución de los personajes de Leonor y Estrella dentro de su apartamento. Esta construcción entre personajes se da mediante un bocadillo en La hija de un ladrón: el padre le hace escupir a su hija el bocadillo al que le ha invitado él cuando Sara le anuncia que quiere la custodia de su hermano, ese mismo bocadillo que Sara le ofrecerá la noche en la que el padre le promete que irán a vivir juntos. Verano 1993 nos brinda otro ejemplo

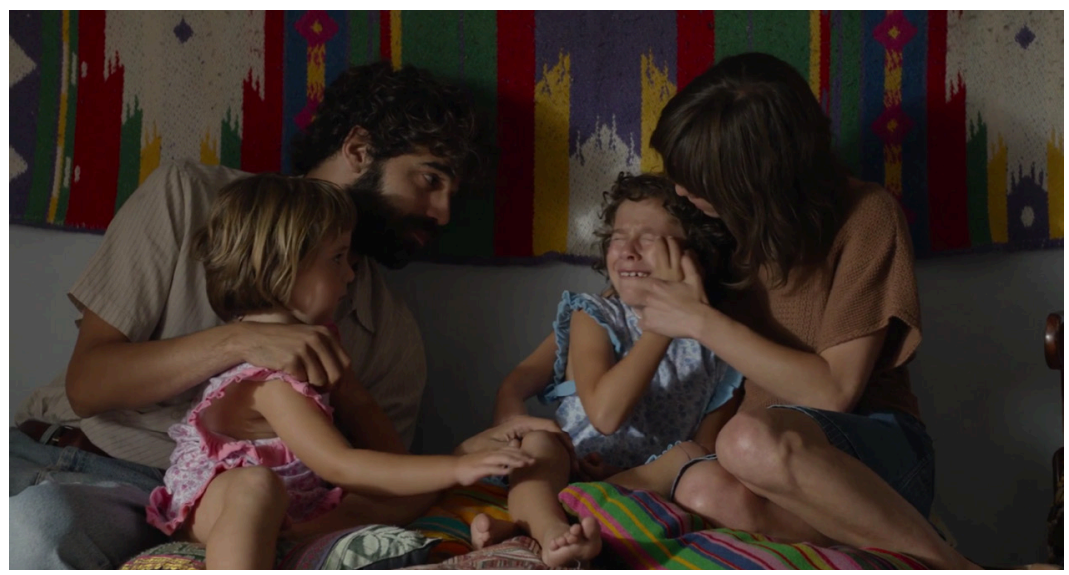

[23] Carlos Heredero, «Directoras españolas en el siglo XXI. Un combate por el equilibrio», p. 172.

[24] Eulàlia Iglesias, «La década en que dejamos de ser la excepción», p. 56.

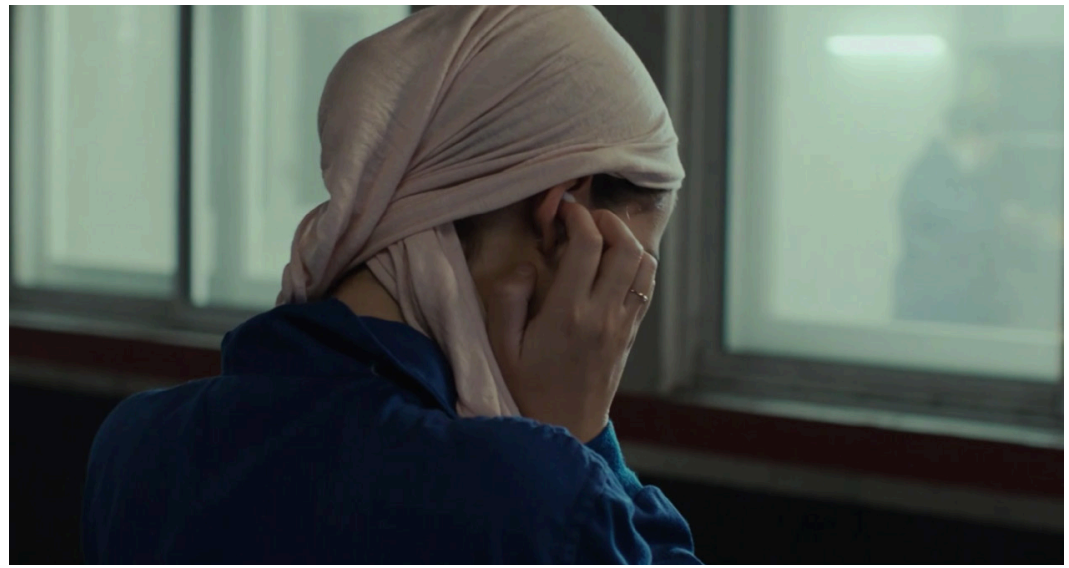

De la parálisis del cuerpo a la lágrima. Arriba, el viaje emocional de Verano 1993 (Carla Simón, 2017); abajo, La hija de un ladrón (Belén Funes, 2019). 
a través de unos zapatos que Frida no se ata para rebelarse contra su madre adoptiva, un gesto que, en cambio, sí mostrará cuando decide abandonar su nueva casa.

En suma, a través de los gestos y los objetos, este grupo de cineastas conciben su forma de escribir, renunciando, en términos de Heredero, «a cualquier arco narrativo construido con los procedimientos tradicionales (intriga, nudos y desenlaces, giros de guion, carpintería dramatúrgica)». ${ }^{23}$ Quizás porque lo que lleva a estas cineastas a hacer cine no tiene tanto que ver con el artificio, sino con la oportunidad que este ofrece para explorar las relaciones humanas. Por eso la familia es su lugar narrativo favorito, porque se trata de un terreno inagotable en lo que concierne a las relaciones, porque en la familia el pasado siempre está presente y sitúa al personaje delante de relaciones tan ineludibles como necesarias. Y, para acabar, de este interés por las relaciones surge, también, un interés por dialogar con la realidad: desde la elección de rostros que han pasado por la experiencia del personaje (La hija de un ladrón) a la introducción de elementos autobiográficos (Family Tour, Verano 1993), rodando en los mismos sitios que fueron inspiración de sus obras (Con el viento, Viaje al cuarto de una madre) u olvidando el guion para dejar que, durante el rodaje, se revelen destellos de verdad.

Junto con los procesos compartidos en la escritura, el rodaje o el montaje, los diálogos narrativos y estéticos que hallamos en las películas de estas jóvenes cineastas revelan que nos encontramos delante de una generación de directoras que no solo irrumpe con fuerza en la cinematografía española contemporánea, sino que lo hace con conciencia de colectivo. Esto demostraría, en palabras de Eulàlia Iglesias, que «los nombres de mujer ya no son un fenómeno aislado» ${ }^{24}$ y que, si hoy existe una Nova Escola de Barcelona, esta tiene rostro de mujer.

\section{BIBLIOGRAFÍA}

Aidelman, Núria, «La nuca», en Jordi Balló y Alain Bergala (coords.), Motivos visuales del cine (Barcelona, Galaxia Gutenberg, 2016), pp. 175-178.

Bernal, Fernando. «'Me gusta quedarme con lo esencial'. Entrevista con Celia Rico» (Caimán, 74, 2018), p. 44.

Blot-Labarrère, Christiane, Marguerite Duras (París, Seuil, 1992).

Carballo, Samuel y Herrero, Beatriz, «Negociación y ruptura en Tres días con la familia: la nueva generación del melodrama familiar» (Revista Comunicación, 10, vol. 1, 2012), pp. 975-990.

ColaizzI, Giulia. «Mar Coll: horizontes de crisis», en Fran A. Zurian (ed.), Miradas de mujer. Cineastas españolas para el siglo XXI (Madrid, Fundamentos, 2017), pp. 109-122.

ComAS, Àngel. Vint anys d'història del cinema a Catalunya (1990-2009) (Barcelona, Laertes, 2010).

Engel, Philip, «Generación Ágata» (Fotogramas, 2085, julio 2017), pp. 96-101.

Heredero, Carlos F., «Directoras españolas en el siglo XXI. Un combate por el equilibrio», en Andrea Morán y Jara Yáñez (eds.), Femenino plural. Mujeres cineastas del siglo XXI (Valladolid, SEMINCI, 2017), pp. 159-183.

—, «Habitar las películas. Entrevista con Meritxell Colell» (Caimán, 76, 2018), p. 69. 
IGLESIAS, Eulàlia, «La década en que dejamos de ser la excepción» (Caimán, 90, 2020), pp. 56-59.

LEJEUnE, Philippe, El pacto autobiográfico y otros estudios (Madrid, Megazul-Endymion, 1994).

Losilla, Carlos, «Una cuestión de tono. Entrevista con Nely Reguera» (Caimán, 55, 2016), pp. 32-33.

Porte, Michèle, Los espacios de Marguerite Duras (Madrid, Ediciones del Oriente y del Mediterráneo, 2011).

Quintana, Àngel, «Madrid versus Barcelona. O el realismo tímido frente a las hibridaciones de la ficción», en Hilario J. Rodríguez (coord.), Miradas para un nuevo milenio. Fragmentos para una historia futura del cine español (Madrid, Festival de Cine de Alcalá de Henares, 2006). pp. 280-284.

—, (2019), «Cuando se pierde la inocencia. La hija de un ladrón» (Caimán, 88, 2019), pp. 22-23.

Scholz, Annette, «Las invisibles del cine español», en Annette Scholz y Marta Álvarez (eds.), Cineastas emergentes. Mujeres en el cine del siglo XXI (Madrid, Iberoamericana, 2018), pp. 45-67.

ZECCHI, Barbara, Desenfocadas. Cineastas españolas y discursos de género (Barcelona, Icaria, 2014).

Recibido: 30 de septiembre de 2020

Aceptado para revisión por pares: 12 de diciembre de 2020

Aceptado para publicación: 22 de febrero de 2021 